Article

\title{
Synthesis of Phosphazene-Containing, Bisphenol A-Based Benzoxazines and Properties of Corresponding Polybenzoxazines
}

\author{
Igor S. Sirotin *(D), Igor A. Sarychev ${ }^{D}$, Viktoria V. Vorobyeva, Anastasia A. Kuzmich, \\ Natalia V. Bornosuz, Denis V. Onuchin, Irina Yu. Gorbunova and Vyacheslav V. Kireev \\ Mendeleev University of Chemical Technology of Russia, 125047, Miusskaya sq. 9, Moscow 125047, Russia; \\ yahoo123-92@mail.ru (I.A.S.); vorobyevavv1995@mail.ru (V.V.V.); akuzmich@muctr.ru (A.A.K.); \\ bornosuz@muctr.ru (N.V.B.); donuchin@muctr.ru (D.V.O.); igorbunova@muctr.ru (I.Y.G.); \\ kireev@muctr.ru (V.V.K.) \\ * Correspondence: isirotin@muctr.ru; Tel.: +7-(499)-978-91-98
}

Received: 13 May 2020; Accepted: 26 May 2020; Published: 28 May 2020

check for updates

\begin{abstract}
With the aim of obtaining halogen-free polybenzoxazazines with reduced flammability, phosphazene-containing benzoxazines (PhBZ) were synthesized in a two-stage method. In the first stage of the reaction of hexachlorocycotriphosphazene with bisphenol A at molar ratios of 1:12, 1:16, and 1:24, respectively, mixtures of bisphenol and hydroxyaryloxycyclotriphosphazenes were

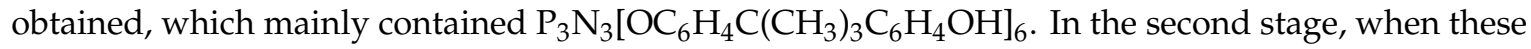
mixtures interacted with aniline and an excess of paraformaldehyde in toluene at $80-90{ }^{\circ} \mathrm{C}, \mathrm{PhBZ}$ containing $20-50 \%$ of the phosphazene component with $\mathrm{M}_{\mathrm{w}} 1200-5800$ were formed. According to ${ }^{1} \mathrm{H}$ and ${ }^{13} \mathrm{C}$ NMR spectroscopy, PhBZ contain a small amount of oligomeric compounds with Mannich aminomethylene bridges. With an increase of the content of the phosphazene component, the curing temperature of PhBZ decreases from $242{ }^{\circ} \mathrm{C}$ to $215^{\circ} \mathrm{C}$. Cured PhBZ samples with a phosphorus content of more than $1.5 \%$ have increased flammability resistance according to UL-94.
\end{abstract}

Keywords: benzoxazine; phosphazene; bisphenol A; hexachlorocyclotriphosphazene; polybenzoxazines

\section{Introduction}

Polybenzoxazines (PBZ) are a relatively new class of polymers obtained by thermal ring-opening polymerization of monomeric and oligomeric compounds with oxazine rings without the release of volatile byproducts, which is the main advantage of this class of compounds [1]. Due to the formation of hydrogen bonds in the polymer [2], PBZs have good physicomechanical properties, low water absorption [3], and practically zero curing shrinkage [4]. Despite the reduced combustibility, basic polybenzoxazines (synthesized from $\mathrm{A} / \mathrm{F}$ bisphenols and aniline) have a burning resistance rating of only V-1 in accordance with UL-94; flame retardancy is required to achieve a V-0 rating.

Over the past 20 years, great success has been achieved in the field of the molecular design of benzoxazines; in particular, functional groups such as allyl [5], maleimide [6], carboxyl [7], propargyl [8], and cyanate ester [9], nitrile [10] and others have been introduced into the structure of these monomers.

One of the methods for the modification of PBZ is the introduction into the structure of the initial monomers of organoelement polyfunctional fragments [11], which increase thermal stability and fire resistance. For example, the introduction of polyhedral oligosiloxanes into the structure of PBZs, along with an increase in thermal stability, contributes to the improvement of the their dielectric properties [12].

Phosphazenes also belong to the class of organo-inorganic compounds [13], the presence of which in polymers lowers combustibility [14] and increases heat resistance and degradation temperature [15]. 
Phosphazenes have advantages not only in comparison with unsafe halogen-containing flame retardants, but also in comparison with conventional phosphorus-based flame retardants [16,17] Functional phosphazenes contribute not only to reduced flammability, but may also be used to adjust the mechanical properties of the resulting thermosets [18,19], which make them one of the most promising halogen-free flame retardants. Phosphazene-containing benzoxazines synthesized in [20-23] form high fire resistance compositions during polymerization due to the synergistic effect of phosphorus and nitrogen atoms. However, the typical synthesis methods $[20,23,24]$ of such compounds are multistage (4-5 stages) and complex (as they include the preparation of Schiff base and its subsequent reduction). This reduces the prospects for the use of phosphazene-benzoxazines in applied areas.

In this work, we synthesized oligomeric phosphazene-containing benzoxazines based on bisphenol A with a different content of the phosphazene component by reacting a mixture of oligomeric hydroxyaryloxycyclotriphosphazenes and bisphenol A with aniline and paraformaldehyde. Compared with other known methods for the preparation of phosphazene-containing benzoxazines, the method proposed in this work is more convenient and scalable.

The structure of the precursors and the obtained oligomeric phosphazene-containing benzoxazines was confirmed by ${ }^{1} \mathrm{H},{ }^{13} \mathrm{C}$, and ${ }^{31} \mathrm{P}$ NMR spectroscopy, mass spectrometry, and gel permeation chromatography. The thermal characteristics were investigated using differential scanning calorimetry and thermogravimetric analysis.

\section{Materials and Methods}

\subsection{Starting Materials}

Hexachlorocyclotriphosphazene is a white crystalline substance with a melting point (m.p.) of $113{ }^{\circ} \mathrm{C}$ [25]. Bisphenol A (PJSC Kazanorgsintez, Kazan, Russia) was purified via repeated recrystallization from chlorobenzene to yield a product with a m.p. of $156.5^{\circ} \mathrm{C}$. Aniline (Sigma-Aldrich, St. Louis, MI, USA), a colorless liquid, was distilled twice under vacuum before use; its boiling point (b.p.) is $184^{\circ} \mathrm{C}$. Paraformaldehyde (Ercros, Barcelona, Spain), a white crystalline solid in the form of prills with a paraformaldehyde content of $91 \%$, was used as received; it has a m.p. $120^{\circ} \mathrm{C}$ (decomposes) and a molecular weight of 300-3000. Potassium carbonate (Sigma-Aldrich, St. Louis, MI, USA), a white crystalline substance in the form of powder, soluble in water, was dried in a vacuum at $100{ }^{\circ} \mathrm{C}$ before use. Solvents were purified according to known methods, and their physical characteristics corresponded to literature data [26].

\subsection{Synthesis Methods}

\subsubsection{Synthesis of Model Monomer BA-a}

A $50 \mathrm{~mL}$ round bottom flask equipped with a magnetic stirrer and reflux condenser was charged with $10 \mathrm{~g}(0.0438 \mathrm{~mol})$ of bisphenol A, $8.159 \mathrm{~g}(0.0876 \mathrm{~mol})$ of aniline, and $16 \mathrm{~mL}$ of toluene. The solution was heated to $60{ }^{\circ} \mathrm{C}$ until bisphenol A was completely dissolved. Then, $6.071 \mathrm{~g}(0.184 \mathrm{~mol})$ of paraformaldehyde was loaded. The reaction was carried out at a temperature of $80^{\circ} \mathrm{C}$ for $6 \mathrm{~h}$; then, the reaction mass was dissolved in $50 \mathrm{~mL}$ of toluene, the lower aqueous layer was separated on a separatory funnel, and the upper toluene solution of the product was washed twice with distilled water. The solution of oligomers in toluene was dried with calcined magnesium sulfate and then filtered, the toluene was distilled off under vacuum, and the product was dried at $100{ }^{\circ} \mathrm{C}$. The yield of light-yellow powdery substance was $97 \%$.

\subsubsection{Synthesis of Hydrohyaryloxyphosphazenes (HAP)}

Three different HAPs with different HCP: bisphenol A ratios were synthesized. The amounts of reagents used in each case are shown in Table 1. 
Table 1. The amount of starting reagents for the synthesis of hydroxyaryloxycyclotriphosphazene with a different ratio of HCP: bisphenol A.

\begin{tabular}{|c|c|c|c|c|}
\hline \multirow{2}{*}{ Parameter } & \multirow{2}{*}{ Unit } & \multicolumn{3}{|c|}{$\begin{array}{l}\text { Molar Ratio of HCP: } \\
\text { Bisphenol A }\end{array}$} \\
\hline & & $1: 24$ & 1:16 & 1:12 \\
\hline $\begin{array}{l}\text { The content of the phosphazene component in a mixture with } \\
\text { bisphenol } \mathrm{A}^{1}\end{array}$ & $\mathrm{wt} \%$ & 27 & 40 & 52 \\
\hline Designation of benzoxazines synthesized on these mixtures & - & BP-1 & BP-2 & $\mathrm{BP}-3$ \\
\hline \multirow{2}{*}{ Bisphenol A } & g & 62.97 & 42.0 & 31.5 \\
\hline & mole & 0.276 & 0.184 & 0.138 \\
\hline \multirow{2}{*}{ Aniline } & $\mathrm{g}$ & 2.78 & 2.57 & 2.35 \\
\hline & mole & 0.0298 & 0.0276 & 0.252 \\
\hline \multirow{2}{*}{ Paraformaldehyde } & g & 2.068 & 1.840 & 1.746 \\
\hline & mole & 0.063 & 0.061 & 0.058 \\
\hline
\end{tabular}

${ }^{1}$ Calculated under the assumption that the product consists only of unreacted bisphenol $\mathrm{A}$ and a hexasubstituted reaction product of $\mathrm{HCF}$ and bisphenol $\mathrm{A}\left(\mathrm{P}_{3} \mathrm{~N}_{3}\left(\mathrm{OC}_{6} \mathrm{H}_{4} \mathrm{C}\left(\mathrm{CH}_{3}\right)_{2} \mathrm{C}_{6} \mathrm{H}_{4} \mathrm{OH}\right)_{6}\right)$.

First, $4 \mathrm{~g}$ ( $0.0115 \mathrm{~mol})$ of hexachlorocyclotriphosphazene, a calculated amount of bisphenol A (Table 1), and $200 \mathrm{~mL}$ of acetonitrile were charged into a $500 \mathrm{~mL}$ three-neck round-bottom flask. After dissolving the solid reagents, $19.06 \mathrm{~g}$ of $\mathrm{K}_{2} \mathrm{CO}_{3}(0.138 \mathrm{~mol})$ was added to the solution. The synthesis was carried out at the boiling point of acetonitrile and under stirring for $12 \mathrm{~h}$, sparging the reaction mixture with argon. Next, acetonitrile was distilled off in vacuo, the residue was dissolved in diethyl ether, and a $1 \mathrm{~N}$ aqueous $\mathrm{HCl}$ solution was poured into the solution until an acid reaction with indicator paper occurred. After the formation of two layers, the upper organic layer was separated on a separatory funnel and washed with water until neutral. It was then dried with calcined magnesium sulfate and filtered; diethyl ether was distilled off under vacuum and the product was dried to constant weight in vacuum. A mixture was obtained consisting of oligomeric hydroxyaryloxphosphazenes and unreacted bisphenol A. The yield of white powder products was $90 \%$ of the theoretical maximum.

2.2.3. Synthesis of Phosphazene-Containing Benzoxazines Based on Mixtures of Hydroxyaryloxycyclotriphosphazenes and Bisphenol A

In a $100 \mathrm{~mL}$ round-bottom flask were charged $4 \mathrm{~g}$ of a HArPh mixture, aniline, the calculated amount shown in Table 1 and $30 \mathrm{~mL}$ of toluene. The mixture of oligohydroxyaryloxyphosphazenes and bisphenol A was dissolved in toluene and aniline at a temperature of $110^{\circ} \mathrm{C}$; then, the temperature was lowered to $80^{\circ} \mathrm{C}$ and the calculated amount of paraformaldehyde was added (Table 1). The synthesis was carried out at $85-90^{\circ} \mathrm{C}$ for $8 \mathrm{~h}$. The resulting solution was washed twice in a separatory funnel with distilled water. The toluene solution of the product was dried with calcined magnesium sulfate, and then filtered, and the toluene was distilled off under vacuum. After drying at $100{ }^{\circ} \mathrm{C}$, the yield of a light-yellow powdery product was $88-90 \%$ of the calculated maximum.

The characteristics of the obtained oligomers BP-1, BP-2 and BP-3 are presented hereinafter.

\subsection{Curing of Benzoxazines}

All polybenzoxazines in this work were cured according the following mode: $2 \mathrm{~h}$ at $150{ }^{\circ} \mathrm{C}, 4 \mathrm{~h}$ at $180^{\circ} \mathrm{C}, 4 \mathrm{~h}$ at $190^{\circ} \mathrm{C}, 2 \mathrm{~h}$ at $200^{\circ} \mathrm{C}$. Before curing, the samples were degassed at a temperature of $130^{\circ} \mathrm{C}$ for $1 \mathrm{~h}$. The completeness of the curing process was monitored by the absence of an exothermic effect on the DSC thermogram. 


\subsection{Methods of Analysis}

The and ${ }^{1} \mathrm{H},{ }^{13} \mathrm{C}$ and ${ }^{31} \mathrm{P}$ NMR spectra were measured with a Bruker AV-600 spectrometer (Bruker Corporation, Bremen, Germany) operating at 600, 151 and $243 \mathrm{MHz}$ respectively. For the NMR experiments, the following parameters were as follows: $\left({ }^{1} \mathrm{H}\right)$ acquisition time-2.7 s, relaxation delay-1.0 s, number of scans- $1,\left({ }^{13} \mathrm{C}\right)$ acquisition time $-0.45 \mathrm{~s}$, relaxation delay-0.1 s, number of scans $-150,\left({ }^{31} \mathrm{P}\right)$ acquisition time $-0.485 \mathrm{~s}$, relaxation delay- $0.5 \mathrm{~s}$, and number of scans-18. The temperature of all measurements was $298 \mathrm{~K}$. The chemical shifts of the signals were calculated relative to the signals of tetramethylsilane $\left({ }^{1} \mathrm{H},{ }^{13} \mathrm{C}\right.$ spectra) and phosphoric acid $\left({ }^{31} \mathrm{P}\right.$ spectra), which were used as internal references. Residual ${ }^{1} \mathrm{H}$ resonance from deuterated solvent was used to reference the ${ }^{1} \mathrm{H}$ spectra. The ${ }^{13} \mathrm{C}$ spectra were referenced through the solvent ${ }^{13} \mathrm{C}$ resonance. The ${ }^{31} \mathrm{P}$ spectra were referenced through the deuterated solvent lock. Deuterated chloroform $\left(\mathrm{CDCl}_{3}\right)$ was used as a solvent for all benzoxazines and deuterated dimethyl sulfoxide (d-DMSO) was used as a solvent for the hydroxyaryloxyphosphazene samples. The spectra were processed using the MestReNova Lab software package (Version 14.1, MESTRELAB RESEARCH, S.L, Santiago de Compostela, Spain).

Gel-permeation chromatography (GPC) was carried out on a Shimadzu LC-20 Prominence (Kyoto, Japan) chromatograph equipped with refractometric and UV detector (a wavelength of $264 \mathrm{~nm}$,) and a PSS column (SDV; $300 \mathrm{~mm} \times 8 \mathrm{~mm}$; $1000 \mathrm{~A}$, separation within 100-60,000 Da). Tetrahydrofuran (THF) was used as an eluent $(1 \mathrm{~mL} / \mathrm{min})$. Molecular mass values were estimated with the use of a polystyrene calibration curve.

Spectrophotometric determination of phosphorus was carried out on a Cary-100 instrument (Agilent Technologies, Santa Clara, California, United States). The method for determining phosphorus [27] consists of the preliminary destruction of organic matter with the transfer of phosphorus to the solution in the form of a phosphate ion and its subsequent spectrophotometric determination in the form of a blue phosphorus-molybdenum complex. Method error is $\pm 0.30 \%$ abs.

Differential scanning calorimetry (DSC) was performed on a Netzsch DSC 204 F1 Phoenix instrument (Netzsch, Selb, Germany) in a nitrogen atmosphere $(20 \mathrm{~mL} / \mathrm{min})$ at a heating rate of $10 \mathrm{deg} / \mathrm{min}$ on samples weighing $10 \mathrm{mg}$.

Thermogravimetric analysis (TGA) was carried out on a Netzsch STA Jupiter instrument (Netzsch, Selb, Germany) in corundum crucibles without a cover in air and in an argon stream at a rate of $70 \mathrm{~mL} / \mathrm{min}$ in a temperature range of $50-900{ }^{\circ} \mathrm{C}$ with a heating rate of $20 \mathrm{deg} / \mathrm{min}$. The mass of the samples was $10-16 \mathrm{mg}$.

A MALDI-TOF mass spectrometric analysis was carried out on the Bruker Auto Flex II instrument (Bruker Corporation, Bremen, Germany).

Liquid chromatography-mass spectrometry (LC-MS) with electrospray ionization $\left(\mathrm{ESI}^{+}\right)$was performed on an Agilent 1100 instrument (Agilent Technologies, Santa Clara, California, United States) using gradient elution in an acetonitrile-water system on a $4.6 \mathrm{~mm}$ Reprosil-Pur Basic C18 250 column with an ion trap LC-MSD-Trap-SL.

Limiting oxygen index (LOI) was determined according ASTM D2863. The sample dimensions were $80 \times 10 \times 4 \mathrm{~mm}$.

Flammability tests were performed according UL-94 standard. The samples dimensions were $127 \times 12.7 \times 2 \mathrm{~mm}$.

Tensile strength was determined using a Z010 testing machine (ZwickRoell, Kennesaw, GA, USA).

\section{Results and Discussion}

\subsection{Synthesis of Model Benzoxazines}

It is known that during the synthesis of benzoxazines, side reactions are possible, including the formation of oligomers with Mannich bridges and free phenolic groups. [28]. The synthesis methods that involve the stage of purification from such compounds by washing with an alkaline solution $[29,30]$ are undesirable in our case due to the possible loss of phosphazene oligomers. Therefore, it was 
necessary to develop a synthesis method that would ensure a high yield of oxazine compounds without a purification step.

Toluene was chosen as a solvent, as it is one of the most suitable for the solution synthesis of benzoxazines [31,32]. The use of paraformaldehyde seems to be more convenient due to the possibility of its long-term storage and lower reactivity with respect to the primary amine due to the heterogeneity of the reaction, which reduces the likelihood of the formation of oligomers with Mannich bridges. As reported by Liu [33], the effect of various parameters on the synthesis of benzoxazines was studied, and it was found that an increase in temperature above $100{ }^{\circ} \mathrm{C}$ leads to the loss of formaldehyde from thermally destructible paraformaldehyde, which does not have enough time to react. Therefore, we synthesized benzoxazine oligomers at $80-90{ }^{\circ} \mathrm{C}$ according to the (Scheme 1 ). On the other hand, during the synthesis of benzoxazines in toluene, water is released, in which some part of formaldehyde also dissolves and does not react, leaving the reaction zone. Therefore, we used a $5 \%$ excess of paraformaldehyde relative to the stoichiometric amount, and we also took into account the $91 \%$ purity of paraformaldehyde.<smiles>CC(C)(c1ccc(O)cc1)c1ccc(O)cc1</smiles>

Scheme 1. Synthesis of benzoxazine monomer (BA-a) by the reaction of bisphenol A, aniline and paraformaldehyde.

With this approach, it is possible to obtain benzoxazine oligomers with a minimum amount of free hydroxyl groups that can be formed by the Mannich reaction, and to avoid washing the reaction products with an alkali solution to remove such oligomers. This step is undesirable, since when washing with alkaline water, a toluene solution containing high molecular weight phenolic oligomers, it is difficult to achieve phase separation.

On the ${ }^{1} \mathrm{H}$ NMR spectrum of the reaction products (Figure 1), signals with chemical shifts $\delta_{\mathrm{H}}=4.62 \mathrm{ppm}\left(\mathrm{s}, \mathrm{Ar}-\mathrm{CH}_{2}-\mathrm{N}\right)$ and $5.37 \mathrm{ppm}\left(\mathrm{s}, \mathrm{O}-\mathrm{CH}_{2}-\mathrm{N}\right)$ belonged to the oxazine rings; no significant amounts of Ar- $\mathrm{CH}_{2}-\mathrm{NPh}-\mathrm{CH}_{2}-\mathrm{Ar}-$ fragments formed by the Mannich reaction (Figure 2, marked with dashed line), and chemical shifts in the region of $\delta_{\mathrm{H}}=4.20-4.50 \mathrm{ppm}$ were detected.

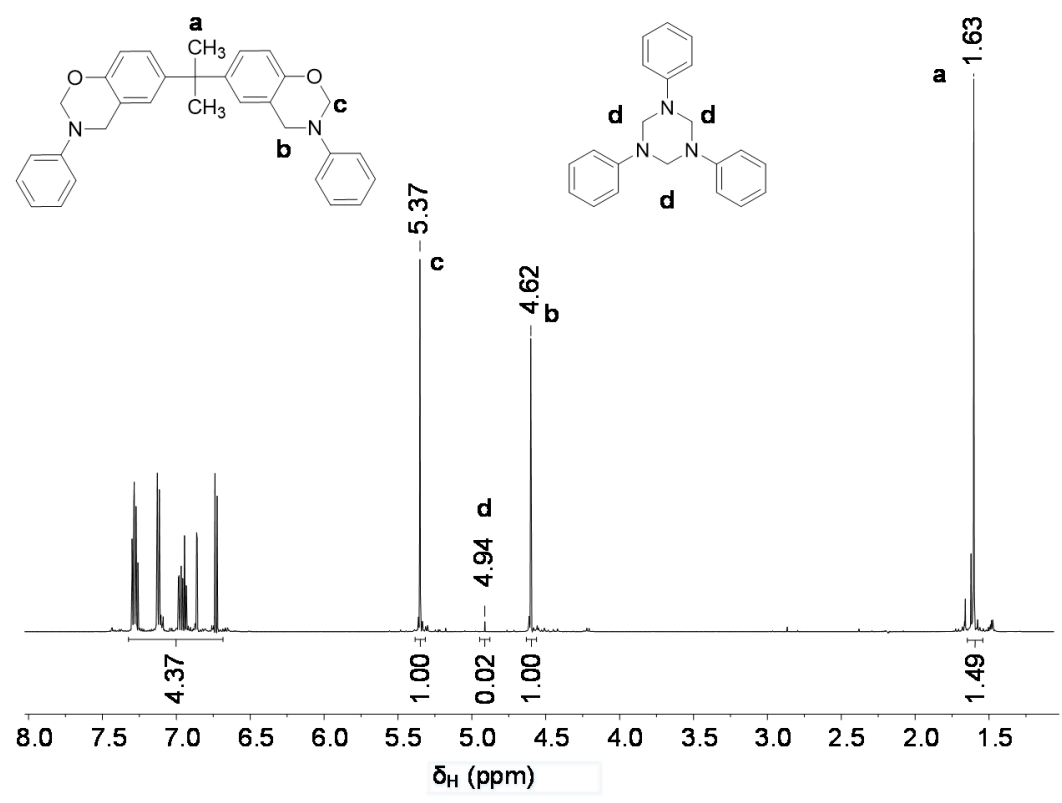

Figure 1. ${ }^{1} \mathrm{H}$ NMR spectrum of BA-a benzoxazine synthesized according to Scheme 1. 
<smiles>C[R14](=O)[O-]</smiles>

$M=1042$

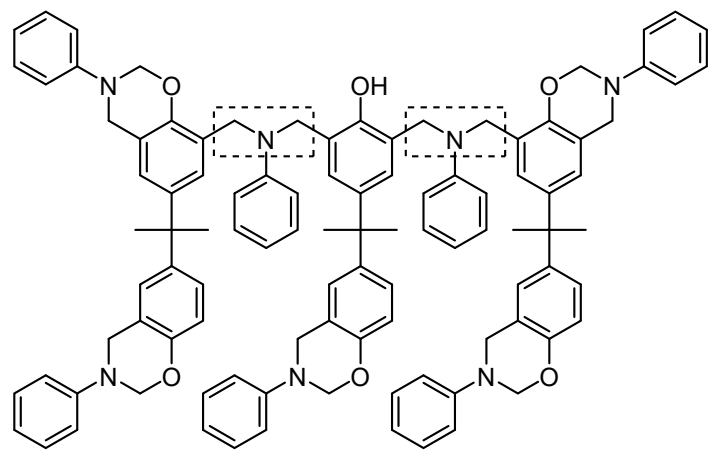

$M=1505$

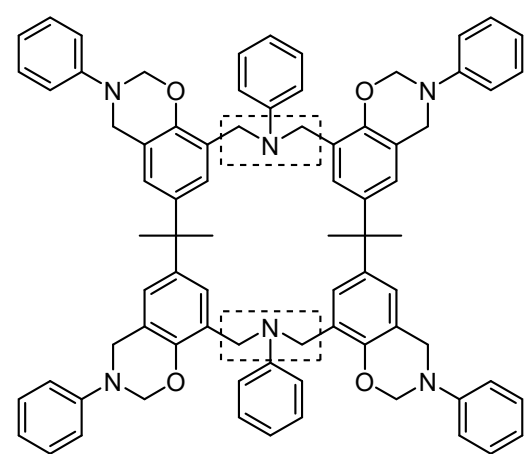

$M=1159$

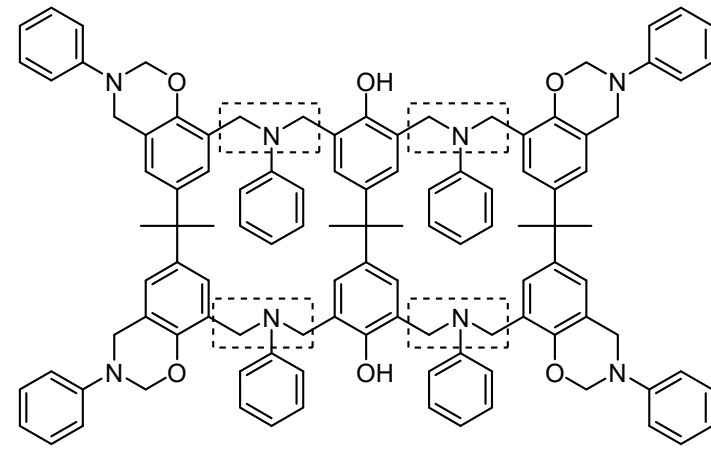

$M=1622$

Figure 2. Formulas of dimers and trimers with aminomethylene Mannich bridges (marked with dashed line), the formation of which is possible during the synthesis of BA-a benzoxazine monomers according to Scheme 1.

Compounds obtained in this way usually contain dimers, trimers and higher molecular weight oligomers [34], the proposed formulas of which are shown in Figure 2.

Unfortunately, MALDI-TOF mass spectrometry was not suitable for identifying compounds with oxazine rings due to intense destruction under desorption-ionization conditions. Therefore, for the detection of high molecular weight impurities, we used liquid chromatography-mass spectrometry (LC-MS) with electrospray ionization (ESI), which had previously been successfully used for the analysis of 1,3-benzoxazines [35]. The mass spectra of the fractions with the exit time from the chromatographic column 13.4, 15.4, and $17.6 \mathrm{~min}$ are shown in Figure 3. The $\mathrm{m} / \mathrm{z}$ values of benzoxazines were found using the formulas $\left[\mathrm{M}+\mathrm{H}+\mathrm{H}_{2} \mathrm{O}-\mathrm{CH}_{2} \mathrm{O}\right]^{+}$or $\left[\mathrm{M}+\mathrm{H}+2 \mathrm{H}_{2} \mathrm{O}-\mathrm{CH}_{2} \mathrm{O}\right]^{+}$, where $\mathrm{M}$ is the molecular weight of the fragment depicted in Figure 4a.

Molecular ions with $\mathrm{m} / \mathrm{z}=439$ (retention time $=13.4 \mathrm{~min}$ ) correspond to dibenzoxazine according to the formula [M+ H+2 $\mathrm{H}_{2} \mathrm{O}-2 \mathrm{CH}_{2} \mathrm{O}$ ] (Figure $4 \mathrm{~b}$ ). With a retention time of $15.4 \mathrm{~min}$, a peak with $\mathrm{m} / \mathrm{z}=558$ appears, which may refer to a molecular ion with two oxazine rings and one aminomethylene bridge $\left[\mathrm{M}+\mathrm{H}+\mathrm{H}_{2} \mathrm{O}-\mathrm{CH}_{2} \mathrm{O}\right]+(569+1+18-30$, Figure $4 \mathrm{c})$; the same peak may refer to a fragment from a benzoxazine dimer, due to destruction under the conditions of analysis. The relative intensity of the main component peak (fraction 1) with a retention time of $13.4 \mathrm{~min}$ is $97 \%$, which indicates a high purity of the benzoxazine monomer. Other possible ion structures generated as a result of the electrospray ionization and their $m / z$ values are presented in Figure $4 \mathrm{~g}-\mathrm{f}$.

Molecular ions with $m / z=785,889$ and 995 observed in the mass-spectrum of the fraction with a retention time of $17.6 \mathrm{~min}$ differ by 104-106 amu, which is close to the mass of the phenylaminomethylene fragment, which is probably formed upon fragmentation of trimeric or higher molecular weight oligomeric benzoxazines. 
(1)

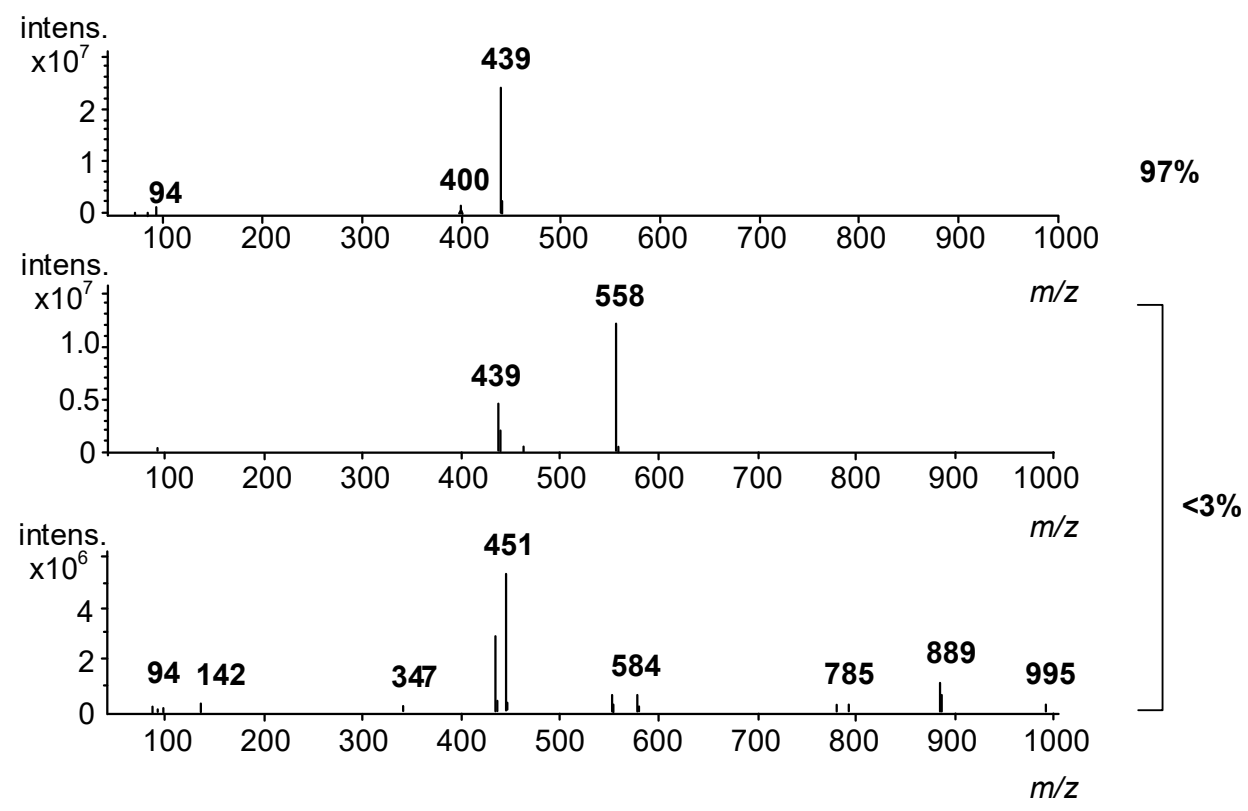

Figure 3. $\mathrm{ESI}^{+}$mass spectra of fractions of benzoxazine synthesized according to Scheme 1. Retention time of fractions: $13.4(\mathbf{1}), 15.4(2)$ and $17.6 \mathrm{~min}(3)$.

(b)

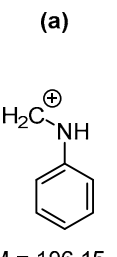

$m / z=439=$

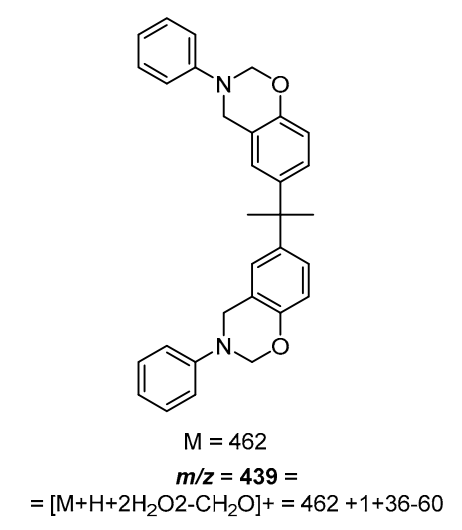

$=\left[\mathrm{M}+\mathrm{H}+2 \mathrm{H}_{2} \mathrm{O} 2-\mathrm{CH}_{2} \mathrm{O}\right]+=462+1+36-60$

(e)

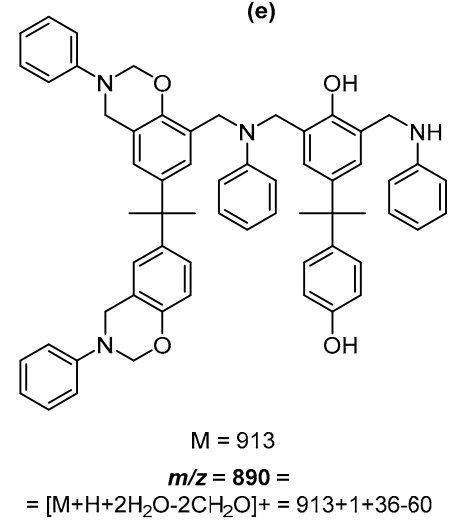

(c)

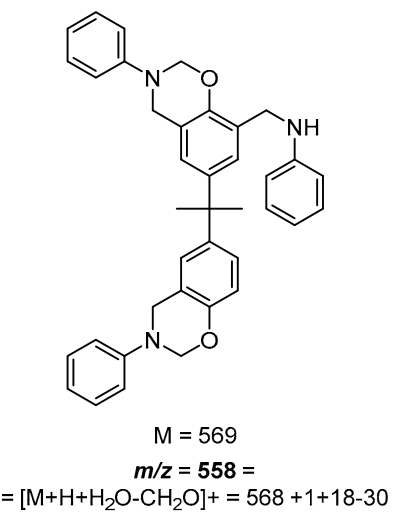

(d)

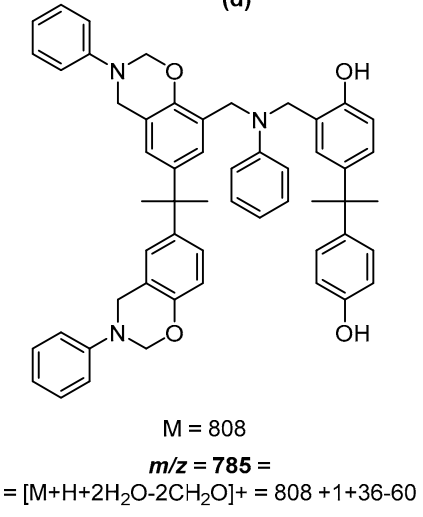

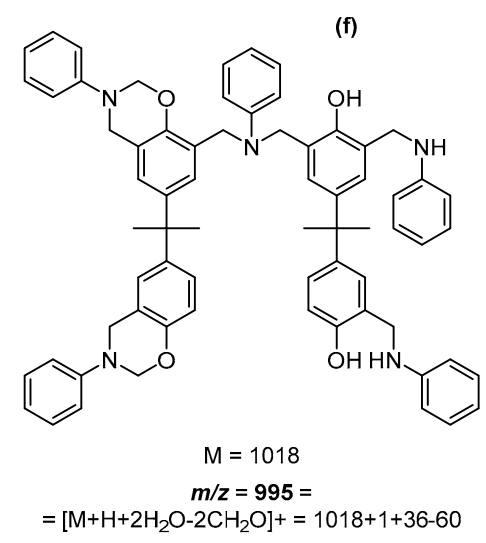

Figure 4. Ion structures and their $m / z$ values formed during mass spectrometry with electrospray ionization of BA-a benzoxazines obtained according to the Scheme 1.: iminium ion derived from phenylaminomethylene fragment (a); fragments with one $(\mathbf{b}, \mathbf{c})$ and two $(\mathbf{d}-\mathbf{f})$ bisphenol moieties. 
Thus, when using excess paraformaldehyde in a one-step synthesis, it is possible to obtain benzoxazine monomers with a minimum amount of oligomers with phenolic hydroxyl groups, which can be formed by the Mannich reaction.

\subsection{Synthesis of Hydroxyaryloxyphosphazene Precursors}

It was previously shown that a convenient method for the synthesis of hydroxyaryloxycyclotri phosphazenes is the use of excess diphenol at the stage of the substitution of chlorine atoms in HCP, which is not subsequently removed, but the obtained mixture of hydroxyaryloxycyclotriphosphazenes and diphenol is used for further transformations [36].

To obtain phosphazene-containing benzoxazine oligomers, we used hydroxyaryloxycyclotri phosphazenes synthesized by the interaction of HCP with an excess of bisphenol A in the presence of an excess of potassium carbonate in an acetonitrile medium (Scheme 2).
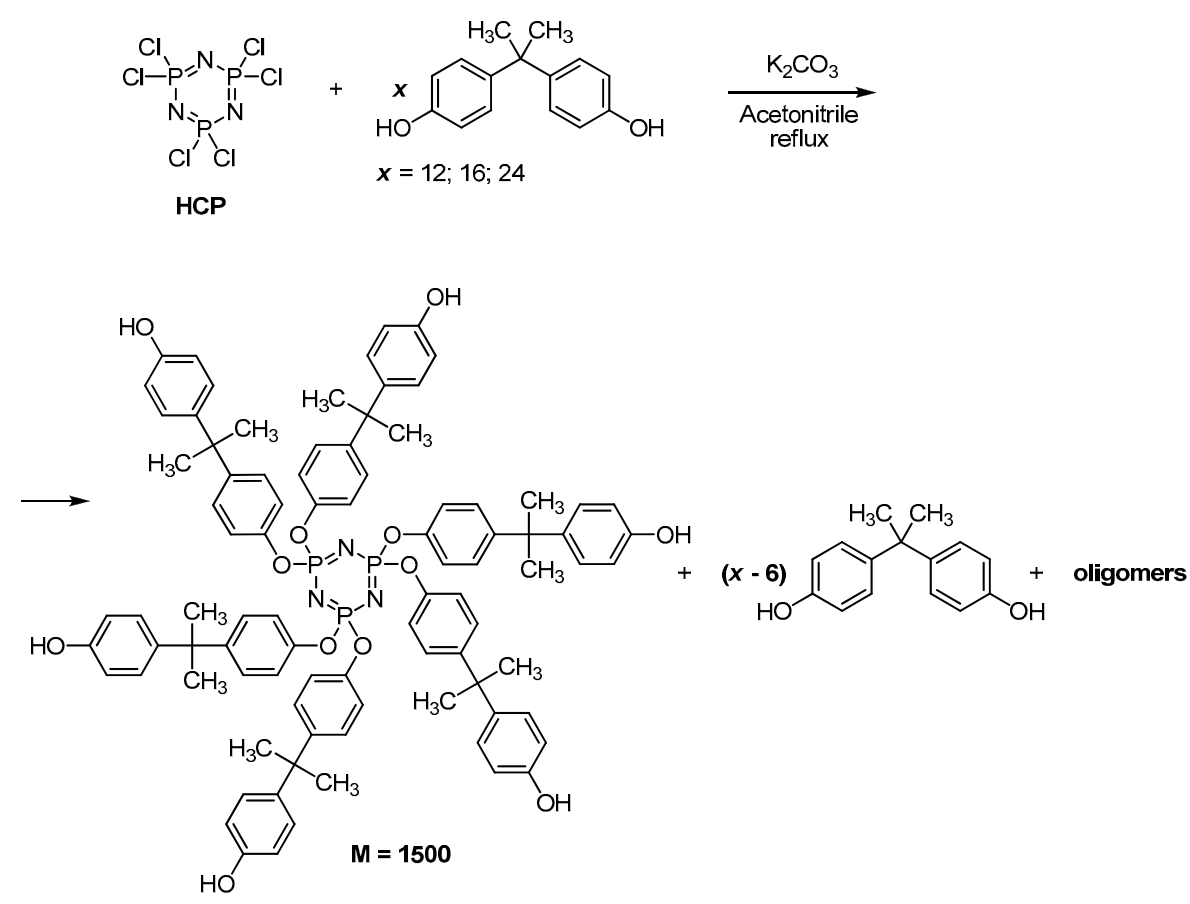

Scheme 2. Synthesis of hydroxyaryloxycyclotriphosphazenes ( $\mathrm{HArPh}$ ) by the reaction of hexachlorocyclotriphosphazene $(\mathrm{HCP})$ and bisphenol A with different molar ratio $(\mathrm{x}=12 ; 16 ; 24)$.

Three hours after the start of the reaction, the signals of phosphorus atoms in the completely substituted cyclotriphosphazene nucleus at $\delta_{\mathrm{p}}=9.86(\mathrm{~s}) \mathrm{ppm}$ and the signals of the $\mathrm{AB}_{2}$ system appeared on the ${ }^{31} \mathrm{P}$ NMR spectrum of reaction products (Figure 5) with $\delta_{\mathrm{A}}=22.96(\mathrm{t}) \mathrm{ppm}$ and $\delta_{\mathrm{B}}=8.13$ (d) ppm, with the latter belong to the pentasubstituted cyclotriphosphazene core. The complete replacement of phosphorus atoms by bisphenol A was achieved after $12 \mathrm{~h}$ at all selected molar ratios of HCP: bisphenol A $(x=12,16,24)$. 


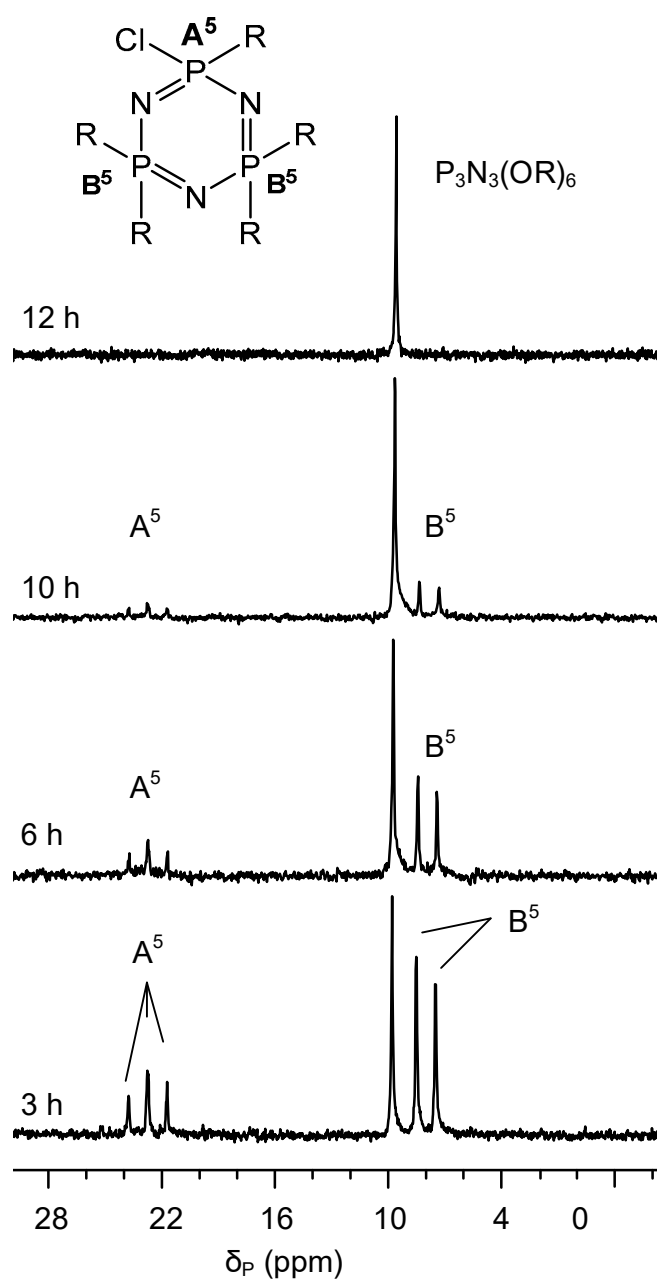

Figure 5. Changes in the ${ }^{31} \mathrm{P}$ NMR spectra of the reaction products of HCP and bisphenol A (1:24) with a process duration of $3-12 \mathrm{~h}$.

On the MALDI-TOF mass spectra of the reaction products obtained with HCP: bisphenol A ratio $=1: 12$ (Figure 6), two main substances are fixed. The main peak of molecular ion $\left[\mathrm{M}_{1}\right]^{+}$with $m / z=1499$ refers to the hexasubstituted derivative. This substance is also probably represented by two cationized particles with $\mathrm{m} / \mathrm{z} 1522$ and 1561. The peak of molecular ion $\left[\mathrm{M}_{2}\right]^{+}$with $\mathrm{m} / \mathrm{z}=2314$ most probably corresponds to cyclolinear oligomers with three bisphenol bridges between two trimeric cycles, respectively:
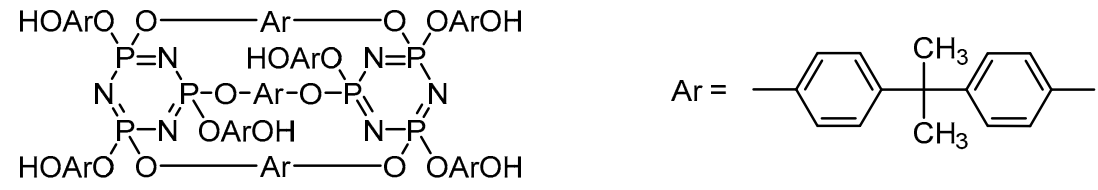

Molecular Weight: 2314

Judging by the intensities of the indicated peak in the MALDI-TOF mass spectra, the number of cyclolinear oligomeric hexahydroxyaryloxycyclotriphosphazenes does not exceed $8 \%$, even when the ratio of $\mathrm{HCP}$ : bisphenol A is 1:12. 


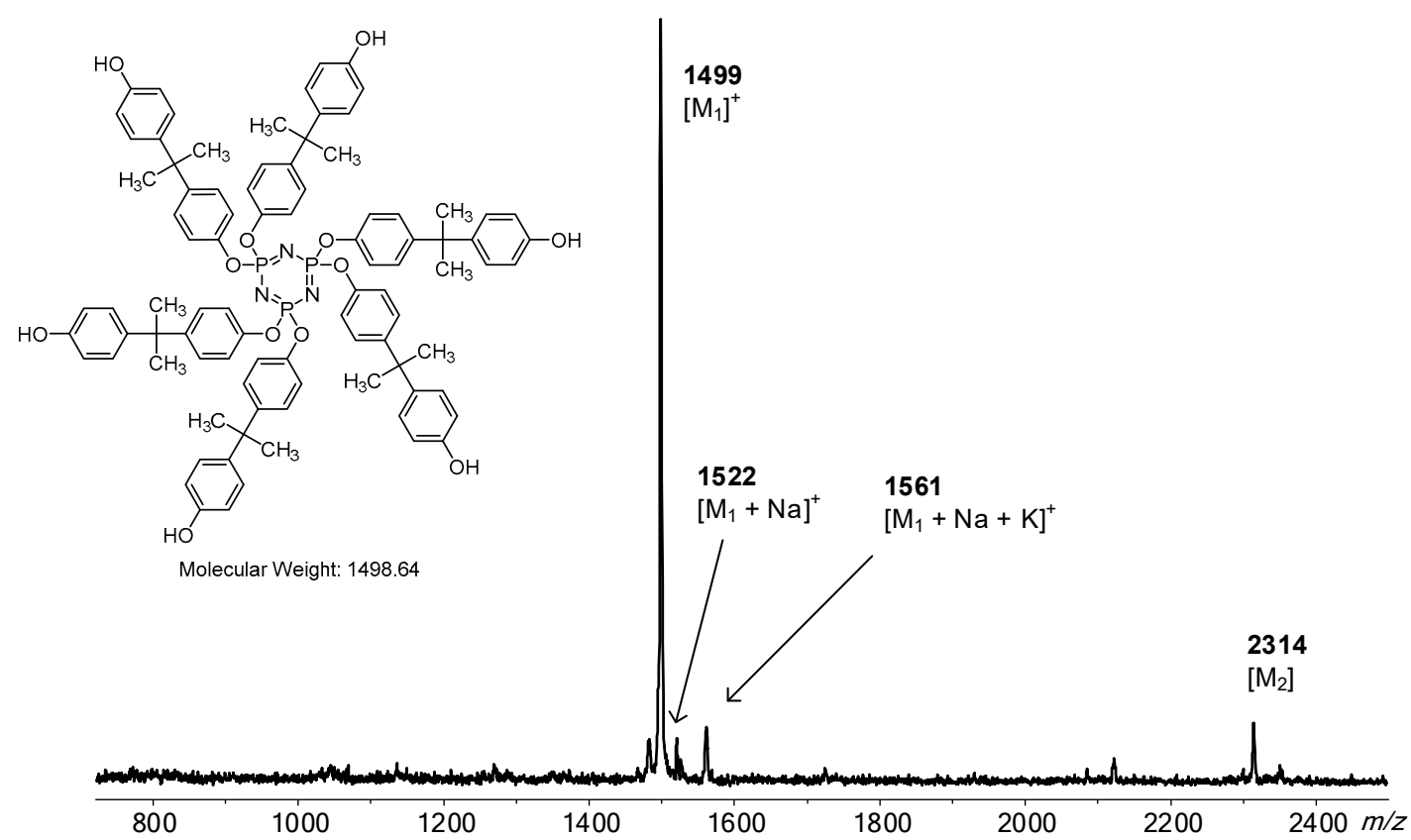

Figure 6. MALDI-TOF mass spectrum of hydroxyaryloxyphosphosphazenes synthesized at a molar ratio of $\mathrm{HCP}$ : bisphenol $\mathrm{A}=1: 12$.

\subsection{Synthesis of Phosphazene-Containing Benzoxazines}

To obtain phosphazene-containing benzoxazines, we previously used synthesized mixtures of oligomeric hydroxyaryloxycyclotriphosphazenes with bisphenol A with different contents of the phosphazene component at ratios HCP: Bisphenol A of 1:24 (BP-1), 1:16 (BP-2) and 1:12 (BP-3) as the initial reagents (Scheme 3, possible side oligomeric products are not shown). The reaction conditions were similar to those for the previously described synthesis of benzoxazine (BA-a) based only on bisphenol A.

On all ${ }^{31} \mathrm{P}$ NMR spectra of phosphazene-containing oligomeric benzoxazines, a singlet signal $\delta_{\mathrm{P}}=9.83 \mathrm{ppm}$ was observed, indicating that the phosphazene cycle structure remains unchanged. The results of ${ }^{1} \mathrm{H}$ and ${ }^{13} \mathrm{C}$ NMR spectroscopy are shown in Table 2, which shows that along with the methylene protons signals of the oxazine ring, $\delta_{\mathrm{H}}=4.62\left(\mathrm{~s}, \mathrm{Ar}-\mathrm{CH}_{2}-\mathrm{NPh}-\right)$ and $\delta_{\mathrm{H}}=5.37 \mathrm{ppm}$ $\left(\mathrm{s}, \mathrm{O}-\mathrm{CH}_{2}-\mathrm{NPh}\right)$, and signals of carbon atoms at $\delta_{\mathrm{C}}=50.70(\mathrm{~s})$ and $79.13(\mathrm{~s}) \mathrm{ppm}$, respectively, there are low-intensity proton signals $\delta_{\mathrm{H}}=4.47(\mathrm{~s}) \mathrm{ppm}$ and carbon $\delta_{\mathrm{C}}=41.81(\mathrm{~s}) \mathrm{ppm}$, which indicate the formation of an insignificant amount of oligomers with the Mannich aminomethylene bridge.

On the ${ }^{13} \mathrm{C}$ NMR spectra (Figure 7), no differences are found in the signals of the carbon atoms of the Mannich aminomethylene bridge; however, differences arise in the chemical shifts of the carbon atoms in the benzene ring of the bisphenol A (Figure 7). In the case when an oxazine ring is formed, the carbon atom in the meta position has a chemical shift of $\delta_{C}=126.4 \mathrm{ppm}$. ("D"), and during oligomerization, it shifts by $\delta_{C}=127.7 \mathrm{ppm}$. This behavior is consistent with that described in the literature for the example of monofunctional benzoxazine monomers $[28,37]$.

As in the case with BA-a, MALDI-TOF mass spectrometry was not suitable for identifying phosphazene compounds with oxazine rings, due to intense destruction under desorption-ionization conditions. We also tried using LC-MS with electrospray ionization to study the high molecular weight phosphazene-benzoxazine fraction in the synthesized products, where 1,3-benzoxazines were also found to undergo fragmentation, but to a much lesser extent when compared to MALDI-TOF. On the $\mathrm{ESI}^{+}$mass spectra (Supplementary information, Figure S5) of the phosphazene-containing benzoxazine BP-1, molecular ions appear with $m / z>1000(1116,1140,1202,1289,1535)$, which, due to the variety of possible oligomeric structures formed by the phosphazene-containing benzoxazines and the fragmentation of molecules with a large number of oxazine rings, are difficult to decipher; 
however, if we compare with the $\mathrm{ESI}^{+}$mass spectra of benzoxazine oligomers without a phosphazene component, it can be assumed that molecular ions with $\mathrm{m} / \mathrm{z}>1000$ belong to phosphazene-containing benzoxazine oligomers.

According to the results of an elemental analysis of all phosphazene-containing products (Table 3), an increased phosphorus content was determined compared to that calculated on the hexasubstituted phosphazene-benzoxazine monomer with six oxazine rings and the bifunctional BA-a monomer, especially in the BP-3 sample. The increased phosphorus content may be due to the presence, in addition to the individual hexazubstituted hydroxyaryloxycyclotriphosphazene based on bisphenol A, of cyclolinear oligomeric hydroxyaryloxycyclotriphosphazenes. The presence of the latter reduces the overall functionality of the phosphazene component at the stage of benzoxazine synthesis, and oligomerization in the phosphazene component at the same stage is possible.

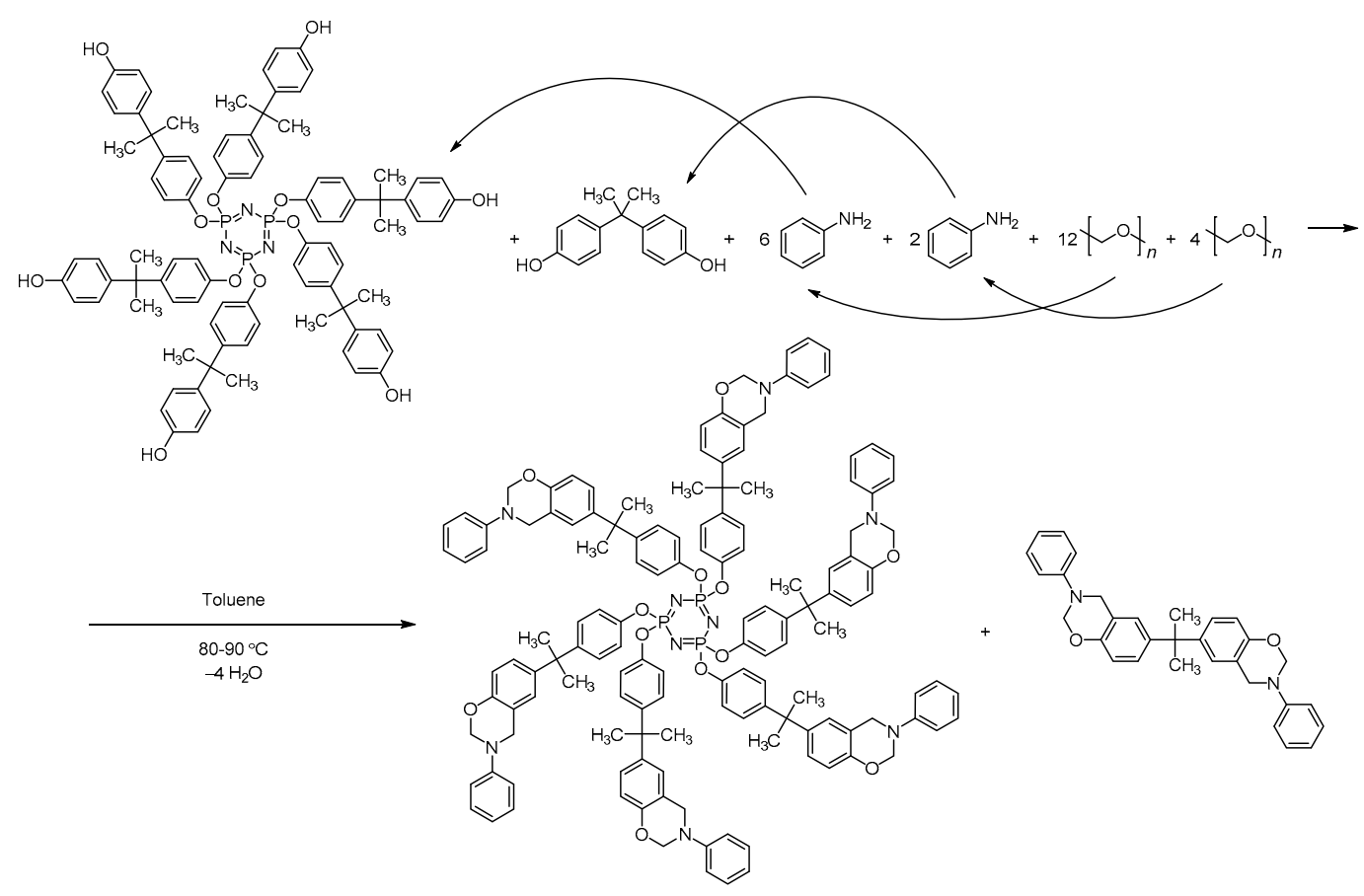

Scheme 3. Synthesis of phosphazene-containing benzoxazines by the reaction of mixture HAP with bisphenol A, aniline and paraformaldehyde with different molar ratio HCP: Bisphenol A of 1:24 (BP-1), 1:16 (BP-2) and 1:12 (BP-3).

Table 2. Results of ${ }^{1} \mathrm{H}$ NMR spectroscopy of BA-a and phosphazene-containing benzoxazines.

\begin{tabular}{|c|c|c|c|c|c|}
\hline \multirow{4}{*}{ Sample } & \multirow{4}{*}{$\begin{array}{l}\text { Phosphazene } \\
\text { Content, \% }\end{array}$} & \multicolumn{4}{|c|}{ Relative ${ }^{1} \mathbf{H}$ Signal Intensity } \\
\hline & & \multicolumn{2}{|c|}{ Benzoxazine Ring } & \multirow{2}{*}{$\begin{array}{c}-\mathrm{CH}_{2}-\mathrm{N}- \\
\text { (Oligomer) }^{1}\end{array}$} & \multirow{2}{*}{$\begin{array}{c}-\mathrm{CH}_{3} \text { of } \\
\text { Bisphenol A }\end{array}$} \\
\hline & & $-\mathrm{CH}_{2}-\mathrm{O}-$ & $-\mathrm{CH}_{2}-\mathrm{N}-$ & & \\
\hline & & $\delta_{H}=5.37(s)$ & $\delta_{\mathrm{H}}=4.62(\mathrm{~s})$ & $\delta_{\mathrm{H}}=4.48(\mathrm{~s})$ & $\delta_{\mathrm{H}}=1.63(\mathrm{~s})$ \\
\hline BA-a & 0 & 1.00 & 1.00 & 0.02 & 1.49 \\
\hline BP-1 & 27 & 1.00 & 1.01 & 0.13 & 2.05 \\
\hline BP-2 & 40 & 1.01 & 0.99 & 0.17 & 2.39 \\
\hline BP-3 & 52 & 1.00 & 1.01 & 0.29 & 3.19 \\
\hline
\end{tabular}

\footnotetext{
${ }^{1}$ Examples of such oligomers and corresponding aminomethylene Mannich bridges are shown on Figure 2.
} 


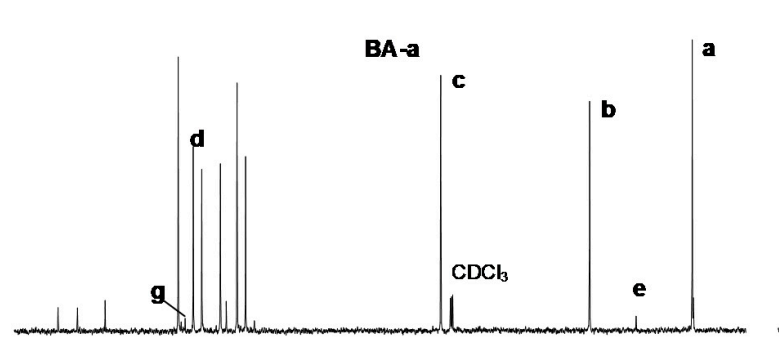

(A)
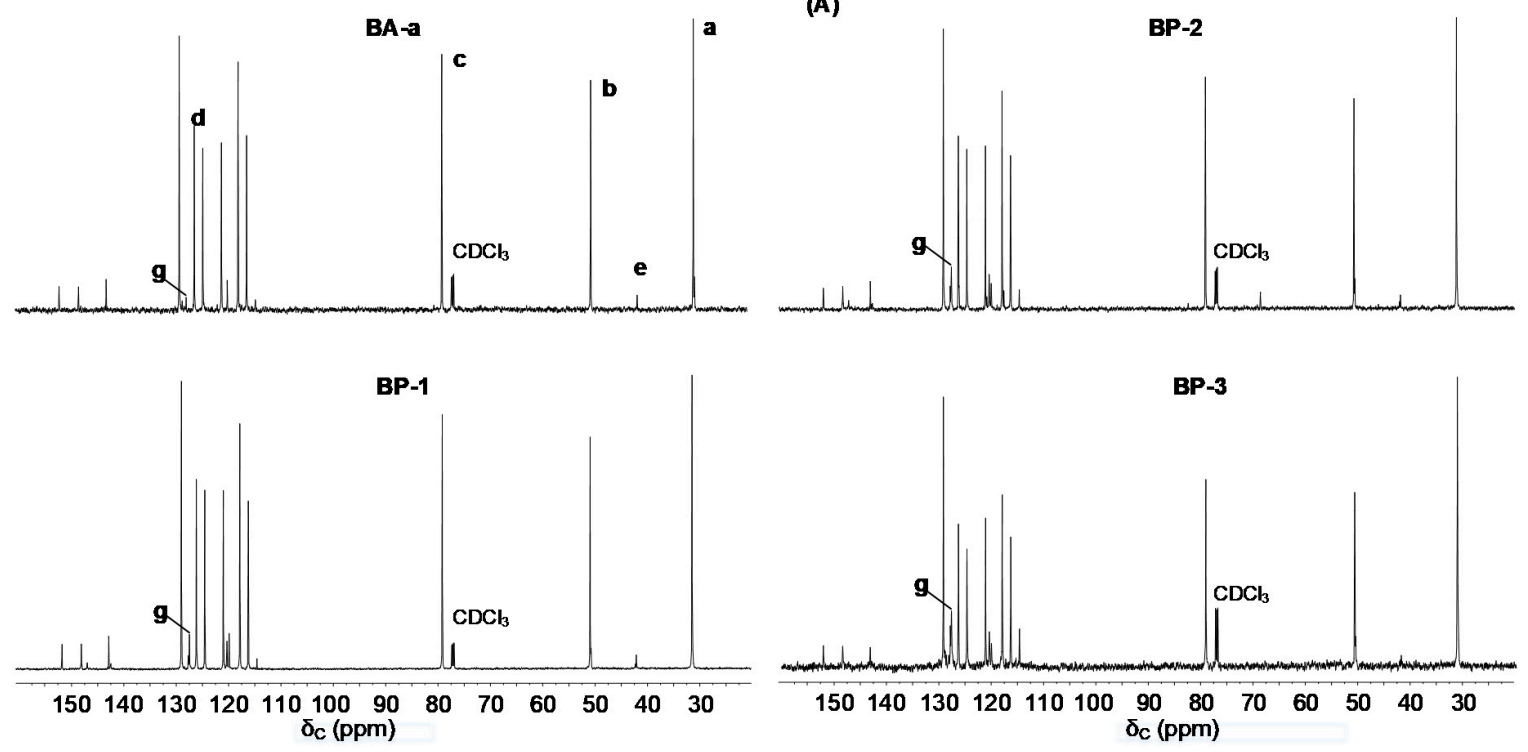<smiles>CC(C)(c1ccc2c(c1)CN(c1ccccc1)CO2)c1ccc2c(c1)CN(c1ccccc1)CO2</smiles>

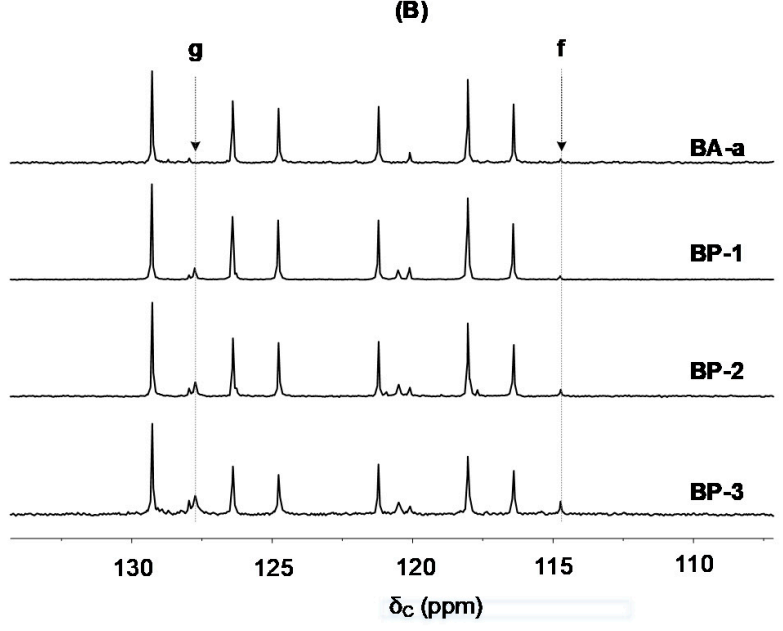

Figure 7. ${ }^{13} \mathrm{C}$ NMR spectra of benzoxazine oligomers (A) and their enlarged fragments (B).

According to gel permeation chromatography (Figure 8, Table 3), the BA-a monomer has $M_{n}=480$, $\mathrm{M}_{\mathrm{w}}=610$. The somewhat overestimated values according to GPC in comparison with the results of mass spectrometry are probably due to the limited applicability of standard polystyrene calibration. Nevertheless, the obtained values of the molecular masses of BA-a are in satisfactory agreement with the actual values of 462 , which allows one to estimate with sufficient accuracy the molecular weight characteristics of phosphazene-containing benzoxazines. In samples BP-1 and BP-2, the values of molecular weights and polydispersity index are in good agreement with those calculated under the assumption that the phosphazene component contains predominantly hexafunctional benzoxazine-phosphazene. The molecular weight distribution of high molecular fractions in both samples is practically the same, only their amounts differs. The average molecular weight of the BP-3 sample, as well as the polydispersity index, is significantly higher than in BP-1 and BP-2, which indicates an increased content of cyclolinear oligomers containing two or more phosphazene cycles in the BP-3 sample. 
Table 3. Molecular weight characteristics and composition of phosphazene-containing benzoxazines.

\begin{tabular}{|c|c|c|c|c|c|}
\hline \multirow{2}{*}{ Sample } & \multirow{2}{*}{$\mathbf{M}_{\mathbf{n}}$} & \multirow{2}{*}{$\mathbf{M}_{\mathbf{w}}$} & \multirow{2}{*}{$\mathbf{M}_{\mathbf{w}} / \mathbf{M}_{\mathbf{n}}$} & \multicolumn{2}{|r|}{ Content (wt\%) } \\
\hline & & & & Phosphorus $^{1}$ & Phosphazene Containing Fraction ${ }^{2}$ \\
\hline BA-a & 480 & 610 & 1.27 & - & - \\
\hline BP-1 & 570 & 1240 & 2.20 & $0.88 / 1.09$ & 20.9/25.8/19.9 \\
\hline BP-2 & 570 & 1830 & 3.23 & $1.36 / 1.61$ & $32.3 / 38.1 / 24.7$ \\
\hline BP-3 & 910 & 5800 & 6.38 & $1.87 / 2.47$ & $44.3 / 58.4 / 49.8$ \\
\hline
\end{tabular}

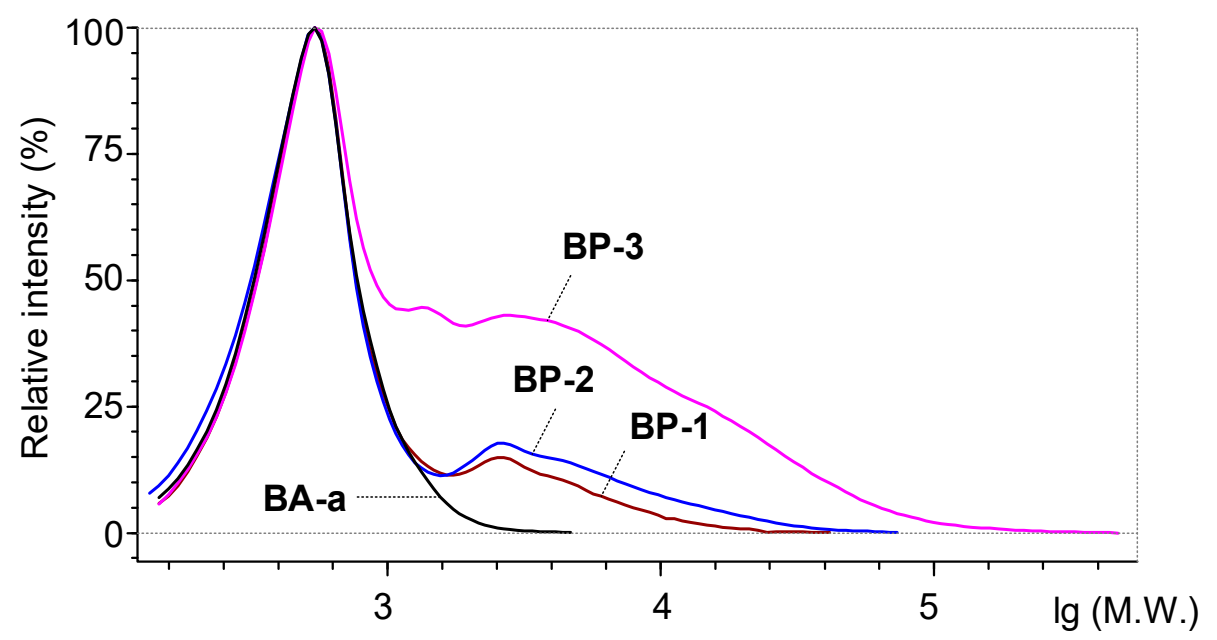

Figure 8. Molecular weight distribution and composition of BA-a benzoxazine and phosphazenecontaining benzoxazines according to GPC.

The contents of the phosphazene component in the obtained mixtures (Table 3), determined by gel permeation chromatography and by elemental analysis of phosphorus, are in satisfactory agreement with each other and with the calculated values.

\subsection{Polymerization of Phosphazene-Containing Benzoxazines and Properties of the Obtained Polybenzoxazines}

The curing process of a series of obtained phosphazene-containing benzoxazine oligomers and BA-a monomer were studied using differential scanning calorimetry. DSC curves are shown in Figure 9, and the results of their analysis are shown in Table 4.

Table 4 shows that with an increase in the content of the phosphazene component in benzoxazines, the curing start temperature, peak temperature, and the thermal effect of the reaction decrease, which is most likely associated with a decrease in the mass fraction of oxazine rings in the product. As in the case of phosphazene-containing epoxies [18,38], a decrease in the curing temperature is observed, which can be attributed to the catalytic effect of phosphazene fragments, which accelerate the opening of benzoxazine rings. Alternatively, phenolic oligomeric impurities can also contribute to lowering the polymerization temperature. 


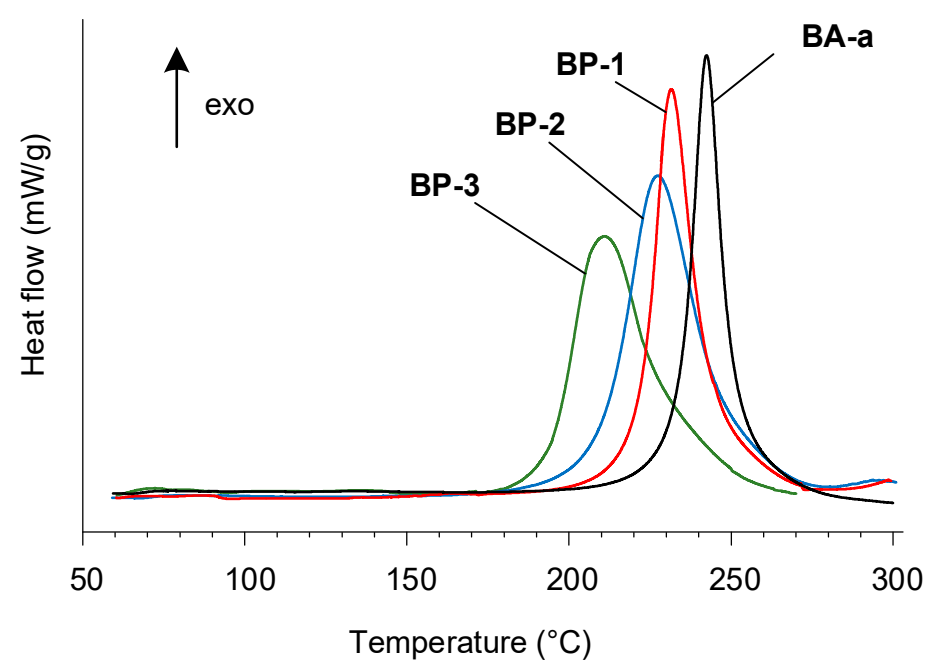

Figure 9. DSC curves of curing of benzoxazine BA-a and phosphazene-containing benzoxazines.

Table 4. DSC results of benzoxazines in the curing process.

\begin{tabular}{|c|c|c|c|c|c|c|}
\hline \multirow{3}{*}{ Sample } & \multicolumn{4}{|c|}{ Exotherm Characteristics } & \multirow{2}{*}{\multicolumn{2}{|c|}{$\begin{array}{l}\text { Relative Benzoxazine } \\
\text { Cycles Content }{ }^{1}\end{array}$}} \\
\hline & \multicolumn{3}{|c|}{ Temperature ${ }^{\circ} \mathrm{C}$} & \multirow{2}{*}{ Polymerization Heat (J/g) } & & \\
\hline & Beginning & Maximal Value & End & & Calculated & Found $^{2}$ \\
\hline BP-3 & 181 & 215 & 248 & 247 & 75.0 & 71.0 \\
\hline BP-2 & 209 & 227 & 250 & 283 & 82.0 & 82.0 \\
\hline BP-1 & 223 & 234 & 247 & 297 & 87.5 & 86.0 \\
\hline BA-a & 233 & 242 & 252 & 346 & 100.0 & 100.0 \\
\hline
\end{tabular}

${ }^{1}$ Regarding the maximum possible, for which the value corresponding to the pure monomer BA-a was taken.

${ }^{2}$ Found by dividing of polymerization heat value of the sample by polymerization heat of BA-a.

The glass transition temperature of PBZ (Table 5) was determined on samples preliminarily cured by temperature modes of $2 \mathrm{~h}$ at $150{ }^{\circ} \mathrm{C}, 4 \mathrm{~h}$ at $180{ }^{\circ} \mathrm{C}, 4 \mathrm{~h}$ at $190{ }^{\circ} \mathrm{C}$ and $2 \mathrm{~h}$ at $200{ }^{\circ} \mathrm{C}$, as well as when rescanning a cured sample directly in the DSC device, cooled to normal temperature. The glass transition temperature of the obtained polybenzoxazines did not change significantly with the increase of phosphazene content, but we observed significant differences in the values of $T_{g}$ of the samples cured according to the given mode and obtained by repeated scanning in a DSC instrument. It was revealed that for the determination of $\mathrm{T}_{\mathrm{g}}$ of PBZ by the DSC method, it is preferable to use previously cured samples. Although when heated at a speed of 10 degrees per minute up to $300^{\circ} \mathrm{C}$, curing occurs completely (which is evidenced by the absence of exothermic effects during repeated scanning), it seems that a defective polymer network is formed, characterized by a lower glass transition temperature. The decrease in the exothermic effect during curing is proportional to the theoretically calculated content of oxazine rings (based on a 100\% yield of BA-a monomer and hexasubstituted phosphazene with six oxazine rings). The reduced content of oxazine rings in the BP-3 sample is associated with the presence of a significant amount of oligophosphazenes with a bisphenol bridge in their structure.

Based on the TGA data (Table 6, detailed description is presented in the supplementary information) obtained in the air atmosphere, it can be concluded that the phosphazene component has a small positive effect both on the initial destruction temperatures and on the char yield. At $550-600{ }^{\circ} \mathrm{C}$, the inhibition of theormoxidative degradation caused by the presence of phosphazene is noticeable (Figure S6a). In an inert atmosphere, the behavior of all samples in the range of $300-800{ }^{\circ} \mathrm{C}$ is very similar (Figure S6b) but, unusually, with an increase in the amount of phosphazene component (phosphorus) in the composition, a decrease in char yield is observed. This may be caused by the loosening of the polymer network in the presence of more phosphazene. The highest char yield of $37 \%$ in an inert medium has the composition BP- 1 with a $25 \%$ content of the phosphazene component. 
Table 5. Thermal and mechanical properties and flammability of polybenzoxazines.

\begin{tabular}{ccccc}
\hline \multirow{2}{*}{ Parameter } & \multicolumn{4}{c}{ Sample } \\
\cline { 2 - 5 } & BA-a & BP-1 & BP-2 & BP-3 \\
\hline Glass transition temperature $\left({ }^{\circ} \mathbf{C}\right)^{\mathbf{1}}$ & $168 / 137$ & $173 / 132$ & $168 / 145$ & $169 / 136$ \\
LOI $^{2}$ & $31 / 23$ & $32 / 29$ & $32 / 31$ & $32 / 32$ \\
UL-94 Rating $_{\text {Tensile strength (MPa) }}$ & 60 & 65 & V- -0 & V-0 \\
Tyyyyy & 64 & 64 & 75
\end{tabular}

${ }^{1}$ Preset curing mode/second scan in a DSC, ${ }^{2}$ Calculated by Van Krevelen and Hoftyzer equation/Determined by ASTM D2863.

Table 6. The results of thermogravimetric analysis of polymers based on BA-a and phosphazenecontaining benzoxazines.

\begin{tabular}{|c|c|c|c|c|c|c|c|c|}
\hline \multirow{2}{*}{ Parameter } & \multicolumn{4}{|c|}{ In Air } & \multicolumn{4}{|c|}{ In Argon } \\
\hline & BA-a & BP-1 & BP-2 & BP-3 & BA-a & BP-1 & BP-2 & BP-3 \\
\hline \multicolumn{9}{|c|}{ Temperature of weight loss $\left({ }^{\circ} \mathrm{C}\right)$} \\
\hline Beginning & 290 & 302 & 312 & 315 & 285 & 303 & 320 & 303 \\
\hline $\mathbf{T}_{\mathbf{5} \%}$ & 318 & 330 & 338 & 336 & 314 & 324 & 338 & 336 \\
\hline $\mathrm{T}_{10 \%}$ & 351 & 365 & 366 & 363 & 347 & 349 & 363 & 359 \\
\hline \multicolumn{9}{|c|}{ Char yield (wt \%) } \\
\hline at $600{ }^{\circ} \mathrm{C}$ & 22 & 32 & 35 & 35 & 35 & 40 & 39 & 38 \\
\hline at $700{ }^{\circ} \mathrm{C}$ & 0 & 9 & 18 & 19 & 34 & 38 & 38 & 36 \\
\hline at $800^{\circ} \mathrm{C}$ & 0 & 1 & 2 & 2 & 33 & 37 & 36 & 35 \\
\hline
\end{tabular}

The values of the limiting oxygen index (LOI) calculated using the empirical Van-CrevelenHovtyzer Equation (1) [39] are 31-32 (Table 5), and are almost independent of the phosphazene content.

$$
\mathrm{LOI}=17.5+0.4 \mathrm{CY}
$$

where $\mathrm{CY}$ is char yield.

At the maximum phosphazene content, the experimental and calculated LOI values (32) are equal (Table 5). Unusually, both the experimental and calculated values of the LOI are quite low. The reason is probably both the abnormally low char yield values of the phosphazene-containing polybenzoxazines obtained in this work (the latter for all phosphazene-containing polybenzoxazines described in the literature are higher than those obtained in this work $[14,20,22-24,40])$, as well as a low phosphorus content (maximum $2.5 \%$ )

Despite this, when the content of phosphazene is more than $30 \%$ (1.5\% phosphorus) in the compositions (BP-2, BP-3), the material has maximum flammability resistance (V-0 rating) according UL-94. Burning stop times of the samples are listed in Table S1. When burning, there is a slight intumescence, which is more noticeable with an increase in the phosphazene content.

Phosphazene-containing benzoxazines in comparison with poly-BA-a are characterized by increased tensile strength (Table 5). The BP-2-based sample has the highest strength, i.e., $84 \mathrm{MPa}$ ( $40 \%$ more than the unmodified sample). With an even higher phosphazene content (BP-3 sample), the strength decreases, remaining higher than that of the unmodified system. Thus, as in epoxy systems [18] modified with functional phosphazene, a dependence with extremum of the mechanical properties on the content of the modifier is observed, with optimal values for a relatively small phosphazene content. However, in the polybenzoxazine system, to achieve the highest strength, about $30 \%$ of the phosphazene modifier is required, while in the epoxy system, only about $10 \%$ is required [18]. 


\section{Conclusions}

The phosphazene-containing functional bisphenol A based benzoxazines obtained in the present work have a phosphazene component content of $20-50 \%$ and a phosphorus content of up to $2.5 \%$. These phosphazene-containing benzoxazines polymerize to form polybenzoxazines with improved flame retardance and mechanical properties, while other characteristics are no worse than conventional polybenzoxazines. Thus, the obtained phosphazene-containing benzoxazines may be used as a component of a binder for composite materials.

Supplementary Materials: The following are available online at http:/www.mdpi.com/2073-4360/12/6/1225/s1, Figure S1. ${ }^{31} \mathrm{P}$ NMR spectrum of phosphazene-containing benzoxazines at HCF: bisphenol A ratios of 1:24 (spectra at ratios of 1:12, 1:16, 1:24 are identical). Figure S2. ${ }^{1} \mathrm{H}$ NMR spectrum of the phosphazene-containing benzoxazine obtained at a ratio of HCF: bisphenol A = 1:24. Figure S3. 1H NMR spectrum of the phosphazene-containing benzoxazine obtained at a ratio of HCF: bisphenol $\mathrm{A}=1: 16$. Figure S4. $1 \mathrm{H}$ NMR spectrum of the phosphazene-containing benzoxazine obtained at a ratio of HCF: bisphenol A = 1:12. Figure S5. ESI + mass spectra of phosphazene-containing benzoxazine. Retention time: A-13.7 min, B-15.1 min, C-16.4 min, D-17.8 min. Figure S6. TGA curves of BA-a and phosphazene-containing benzoxazines based polymers obtained in air (a) and in argon (b). Table S1. Determining the flammability class of samples according to UL-94 standard. Figures S7-10 - ${ }^{1} \mathrm{H}$ NMR spectra of BA-a and phosphazene-containing benzoxazine obtained at a ratios of HCF: bisphenol A of 1:24, 1:16 and 1:12 respectively.

Author Contributions: I.S.S., I.A.S.-planning of the experiments, writing a manuscript; I.A.S., V.V.V.-synthesis of monomers and polymers, interpretation of the results; I.Y.G., A.A.K.-synthesis of intermediate products; N.V.B., D.V.O.—DSC analysis and mechanicals, I.S.S., V.V.K.—conceptualization, general management and editing of the manuscript. All authors have read and agreed to the published version of the manuscript.

Funding: This work is supported by the Russian Science Foundation under grant 19-73-10204.

Acknowledgments: The authors thank M.A. Haskov and M.I. Buzin for help in conducting thermogravimetric analysis and interpretation of its results and R.S. Borisov for the MALDI-TOF analysis.

Conflicts of Interest: The authors declare no conflict of interest.

\section{References}

1. Russell, V.M.; Koenig, J.L.; Low, H.Y.; Ishida, H. Study of the characterization and curing of benzoxazines using 13C solid-state nuclear magnetic resonance. J. Appl. Polym. Sci. 1998, 70, 1413-1425. [CrossRef]

2. Kim, H.D.; Ishida, H. A study on hydrogen-bonded network structure of polybenzoxazines. J. Phys. Chem. A 2002, 106, 3271-3280. [CrossRef]

3. Wang, C.-F.; Chiou, S.-F.; Ko, F.-H.; Chou, C.-T.; Lin, H.-C.; Huang, C.-F.; Chang, F.-C. Fabrication of Biomimetic Super-Amphiphobic Surfaces Through Plasma Modification of Benzoxazine Films. Macromol. Rapid Commun. 2006, 27, 333-337. [CrossRef]

4. Takeichi, T.; Kawauchi, T.; Agag, T. High Performance Polybenzoxazines as a Novel Type of Phenolic Resin. Polym. J. 2008, 40, 1121-1131. [CrossRef]

5. Wang, Y.; Kou, K.; Wu, G.; Feng, A.; Zhuo, L. The effect of bis allyl benzoxazine on the thermal, mechanical and dielectric properties of bismaleimide-cyanate blend polymers. RSC Adv. 2015, 5, 58821-58831. [CrossRef]

6. Jin, L.; Agag, T.; Ishida, H. Bis(benzoxazine-maleimide)s as a novel class of high performance resin: Synthesis and properties. Eur. Polym. J. 2010, 46, 354-363. [CrossRef]

7. Li, S.; Zou, T. Synthesis, Characterization of New Carboxylic Acid-Containing Benzoxazine and Its Cocuring Behaviors with Bisoxazoline. J. Appl. Polym. Sci. 2012, 123. [CrossRef]

8. Agag, T.; Takeichi, T. Novel Benzoxazine Monomers Containing p-Phenyl Propargyl Ether: Polymerization of Monomers and Properties of Polybenzoxazines. Macromolecules 2001, 34, 7257-7263. [CrossRef]

9. Ohashi, S.; Kilbane, J.; Heyl, T.; Ishida, H. Synthesis and Characterization of Cyanate Ester Functional Benzoxazine and Its Polymer. Macromolecules 2015, 48, 8412-8417. [CrossRef]

10. Zhang, H.; Lu, Z. Synthesis and characterization of novel benzoxazines containing nitrile and allyl groups and their polymers. $e$-Polymers 2010, 10. [CrossRef]

11. Chiu, W.-M.; Wang, Y.-X.; Tsai, P.-A.; Wu, J.-H. Preparation and characterization of novel polybenzoxazine hybrid materials. High Perform. Polym. 2016, 28, 971-983. [CrossRef] 
12. Mohamed, M.G.; Kuo, S.-W. Polybenzoxazine/Polyhedral Oligomeric Silsesquioxane (POSS) Nanocomposites. Polymers 2016, 8, 225. [CrossRef]

13. Guglielmi, M.; Colombo, P.; Brusatin, G.; Facchin, G.; Gleria, M. New materials based on the reaction of cyclo- and poly-(organo phosphazenes) with $\mathrm{SiO} 2, \mathrm{TiO} 2$ and $\mathrm{ZrO} 2$ precursors. J. Sol Gel Sci. Technol. 1994, 2, 109-114. [CrossRef]

14. Krishnadevi, K.; Selvaraj, V. Development of halogen-free flame retardant phosphazene and rice husk ash incorporated benzoxazine blended epoxy composites for microelectronic applications. N. J. Chem. 2015, 39, 6555-6567. [CrossRef]

15. Sun, J.; Wang, X.; Wu, D. Novel Spirocyclic Phosphazene-Based Epoxy Resin for Halogen-Free Fire Resistance: Synthesis, Curing Behaviors, and Flammability Characteristics. ACS Appl. Mater. Interfaces 2012, 4, 4047-4061. [CrossRef] [PubMed]

16. Schartel, B. Phosphorus-based Flame Retardancy Mechanisms-Old Hat or a Starting Point for Future Development? Materials 2010, 3, 4710-4745. [CrossRef] [PubMed]

17. Stewart, F.F. Phosphazenes. In Organophosphorus Chemistry; Allen, D.W., Loakes, D., Tebby, J.C., Eds.; Royal Society of Chemistry: London, UK, 2013; Volume 42, pp. 216-262. ISBN 978-1-84973-584-1.

18. Onuchin, D.V.; Sirotin, I.S.; Sarychev, I.A.; Bornosuz, N.V.; Kireev, V.V.; Gorbunova, I.Y.; Gorbatkina, Y.A. Physicochemical Properties of Epoxy Composites Modified with Epoxyphosphazene. Polym. Sci. Ser. B 2019, 61, 286-293. [CrossRef]

19. Machotova, J.; Stranska, E.; Skornok, J.; Zarybnicka, L.; Melanova, K.; Rychly, J.; Ruckerova, A. Fluorine containing self-crosslinking acrylic latexes with reduced flammability and their application as polymer binders for heterogeneous cation-exchange membranes. J. Appl. Polym. Sci. 2017, 134, 45467. [CrossRef]

20. Wu, X.; Zhou, Y.; Liu, S.-Z.; Guo, Y.-N.; Qiu, J.-J.; Liu, C.-M. Highly branched benzoxazine monomer based on cyclotriphosphazene: Synthesis and properties of the monomer and polybenzoxazines. Polymer 2011, 52, 1004-1012. [CrossRef]

21. Ma, H.-X.; Zhao, C.; Qiu, J.-J.; Liu, Y.; Liu, C.-M. Synthesis of branched benzoxazine monomers with high molecular mass, wide processing window, and properties of corresponding polybenzoxazines. J. Appl. Polym. Sci. 2017, 134. [CrossRef]

22. Amarnath, N.; Appavoo, D.; Lochab, B. Eco-Friendly Halogen-Free Flame Retardant Cardanol Polyphosphazene Polybenzoxazine Networks. ACS Sustain. Chem. Eng. 2018, 6, 389-402. [CrossRef]

23. Tan, Z.-W.; Wu, X.; Zhang, M.; Qiu, J.-J.; Liu, C.-M. Synthesis and properties of main-chain oligomeric benzoxazine precursor containing cyclotriphosphazene units. High Perform. Polym. 2014, 26, 906-913. [CrossRef]

24. Wu, X.; Liu, S.-Z.; Tian, D.-T.; Qiu, J.-J.; Liu, C.-M. Well-defined organic-inorganic hybrid benzoxazine monomers based on cyclotriphosphazene: Synthesis, properties of the monomers and polybenzoxazines. Polymer 2011, 52, 4235-4245. [CrossRef]

25. Sirotin, I.S.; Bilichenko, Y.V.; Suraeva, O.V.; Solodukhin, A.N.; Kireev, V.V. Synthesis of oligomeric chlorophosphazenes in the presence of $\mathrm{ZnCl}_{2}$. Polym. Sci. Ser. B 2013, 55, 63-68. [CrossRef]

26. Riddick, J.A.; Bunger, W.B.; Sakano, T.K. Organic Solvents: Physical Properties and Methods of Purification; Wiley: Hoboken, NJ, USA, 1986; ISBN 978-0-471-08467-9.

27. Gelman, N.E. Methods of Quantitative Organic Elemental Microanalysis; Khimiya: Moscow, Russia, 1987.

28. Ishida, H.; Krus, C.M. Synthesis and Characterization of Structurally Uniform Model Oligomers of Polybenzoxazine. Macromolecules 1998, 31, 2409-2418. [CrossRef]

29. Ishida, H. Process for Preparation of Benzoxazine Compounds in Solventless Systems. U.S. Patent 5,543,516, 18 May 1994.

30. Ning, X.; Ishida, H. Phenolic materials via ring-opening polymerization: Synthesis and characterization of bisphenol-A based benzoxazines and their polymers. J. Polym. Sci. Part A Polym. Chem. 1994, 32, 1121-1129. [CrossRef]

31. Wang, D.; Kincaid, D.S. Method for Producing Benzoxazine Compounds. U.S. Patent Application 20140148597, 24 July 2012.

32. Aizawa, T.; Hirai, Y.; Numata, S. Method for producing benzoxazine resin. U.S. Patent Application 20040138345, 12 March 2002.

33. Liu, J. Synthesis, Characterization, Reaction Mechanism and Kinetics of 3,4-dihydro-2H-1,3-benzoxazine and Its Polymer. Ph.D. Thesis, Case Western Reserve University, Cleveland, OH, USA, 1995. 
34. Jun Ko, Y.; Kieu Giang, T.; Yoo, H.; Hwan Kim, J. Structural Study of Bisphenol-A Benzoxazine by Tandem Mass Analysis. Adv. Mater. Res. 2012, 560-561, 62-65. [CrossRef]

35. Puchot, L.; Verge, P.; Fouquet, T.; Vancaeyzeele, C.; Vidal, F.; Habibi, Y. Breaking the symmetry of dibenzoxazines: A paradigm to tailor the design of bio-based thermosets. Green Chem. 2016, 18, 3346-3353. [CrossRef]

36. Sirotin, I.S.; Bilichenko, Y.V.; Brigadnov, K.A.; Kireev, V.V.; Suraeva, O.V.; Borisov, R.S. Oligomeric hydroxy-aryloxy phosphazene based on cyclic chlorophosphazenes. Russ. J. Appl. Chem. 2013, 86, 1903-1912. [CrossRef]

37. Dunkers, J.; Ishida, H. Vibrational assignments of 3-alkyl-3,4-dihydro-6-methyl-2H-1,3-benzoxazines in the fingerprint region. Spectrochim. Acta Part A Mol. Biomol. Spectrosc. 1995, 51, 1061-1074. [CrossRef]

38. Onuchin, D.V.; Sirotin, I.S.; Pavlova, G.A.; Filatov, S.N.; Kireev, V.V.; Kerber, M.L.; Gorbunova, I.Y. Features of Curing of a Diane Epoxy Oligomer Modified with Epoxyphosphazene. Polym. Sci. Ser. B 2018, 60, 182-187. [CrossRef]

39. Van Krevelen, D.W.; Krevelen, D.W.; Nijenhuis, K. Properties of Polymers: Their Correlation with Chemical Structure; Their Numerical Estimation and Prediction from Additive Group Contributions; Elsevier: Amsterdam, The Netherlands, 2009; ISBN 978-0-08-054819-7.

40. Tan,Z.-W.; Wu, X.; Zhang, M.; Qiu, J.-J.; Liu, C.-M. Performances improvement of traditional polybenzoxazines by copolymerizing with cyclotriphosphazene-based benzoxazine monomers. Polym. Bull. 2015, 72, 1417-1431. [CrossRef]

(C) 2020 by the authors. Licensee MDPI, Basel, Switzerland. This article is an open access article distributed under the terms and conditions of the Creative Commons Attribution (CC BY) license (http://creativecommons.org/licenses/by/4.0/). 